\title{
Auscultatory characteristics of normally functioning Lillehei-Kaster, Björk-Shiley, and St Jude heart valve prostheses
}

\author{
MARKKU KUPARI, * ARI HARJULA, $\dagger$ SEVERI MATTILA $\dagger$ \\ From the ${ }^{\star}$ First Department of Medicine, and the $\dagger$ Department of Thoracic and Cardiovascular Surgery, \\ Helsinki University Central Hospital, Helsinki, Finland
}

SUMMARY Auscultatory and echocardiographic and phonocardiographic studies were performed on 26 patients who had a total of 11 Lillehei-Kaster, 16 Björk-Shiley, and $18 \mathrm{St}$ Jude heart valve prostheses functioning normally in the aortic or mitral positions or both. With all types and positions of prostheses a distinct closing sound was always detected. It was frequently heard in two parts which, according to echocardiographic and phonocardiographic studies, resulted from the onset and completion of the valve closure. An opening sound could be heard from all BjörkShiley and St Jude valves but from only four of the 11 Lillehei-Kaster valves. The opening sounds due to mitral prostheses consisted of two to three closely spaced clicks detected as a faint early diastolic crackle on auscultation. Echocardiography with phonocardiography indicated that they were related to the onset and termination of the disc opening excursion. In the aortic position the valves always produced early to mid-systolic murmurs, and a soft early diastolic murmur was also heard in seven of 23 patients. A mid-diastolic rumble was heard in 12 of 22 patients with mitral prostheses.

Normally functioning tilting disc valve prostheses produce characteristic auscultatory findings, and familiarity with these findings will be useful in clinical evaluation of patients with these prostheses.

The development and adoption of more and more sophisticated diagnostic techniques may have overshadowed the value of simple clinical skills in cardiology. The latest trends in the assessment of prosthetic heart valve function are an example of this. Although cardiac auscultation was used to evaluate the ball-in-cage valves of the $1960 \mathrm{~s}^{1}{ }^{1}$ noninvasive studies of the more recently introduced tilting disc valves have relied mainly on echocardiography and phonocardiography, ${ }^{2-4}$ cinefluoroscopy, ${ }^{56}$ or Doppler echocardiography. ${ }^{78}$ Not one original investigation describes in detail the valves' auscultatory characteristics. Yet, as Mintz et al have shown, ${ }^{9}$ careful auscultation may be more sensitive and more specific than echocardiography

Requests for reprints to Dr Markku Kupari, Cardiovascular Laboratory, Helsinki University Central Hospital, 00290 Helsinki, Finland.

Accepted for publication 18 November 1985 and phonocardiography or cinefluoroscopy in detecting prosthesis malfunction. To identify an abnormality the clinician must become familiar with the range of normal findings associated with the most commonly used prosthetic valves.

We describe the auscultatory characteristics of normally functioning Lillehei-Kaster, Björk-Shiley, and St Jude prostheses in a group of patients who had had uneventful double valve operation at our hospital. To confirm and explain the auscultatory observations we also present the relevant echocardiographic and phonocardiographic findings in these patients.

\section{Patients and methods}

The study group consisted of 26 patients (nine men and 17 women; mean age 56 years, range 32-69) who had normally functioning uni-leaflet or bi-leaflet tilting disc valve prostheses in the aortic or mitral 
positions or both. They were examined in July-August 1983, a mean of 37 months after operation (range five months to 10 years). Routine physical examination, 12 lead electrocardiogram, chest $x$ ray, and laboratory tests were also performed. Prosthetic valve function was judged to be normal if there had been $(a)$ an uncomplicated postoperative course; (b) no embolic episodes; (c) no clinical signs or symptoms of prosthesis obstruction or paravalvar regurgitation; $(d)$ no haemolytic anaemia; and $(e)$ normal movements of the valve $\operatorname{disc}(s)$ on echocardiography, provided the examination was of technically acceptable quality. Most patients had undergone double valve replacement and a total of 45 tilting disc valve prostheses had been implanted, 23 in the aortic and 22 in the mitral position. These included 11 Lillehei-Kaster, 16 Björk-Shiley, and 18 St Jude valves. At the time of our study 13 patients were in sinus rhythm and 13 had atrial fibrillation.

\section{AUSCULTATION}

We performed cardiac auscultation over different

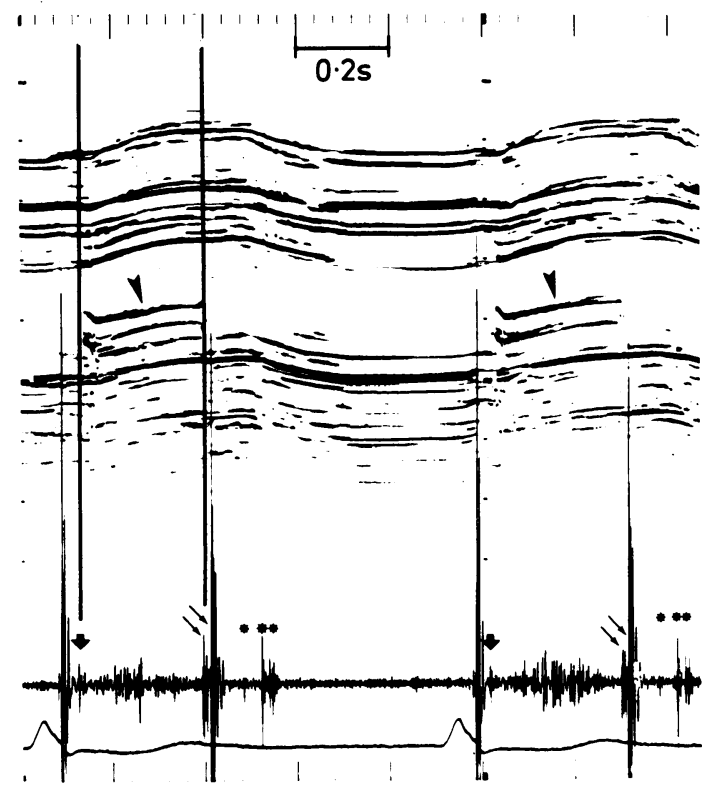

Fig. 1 Echophonocardiogram of a Lillehei-Kaster aortic valve prosthesis showing the motion of the disc (arrowheads) within the aortic root and the simultaneous phonocardiogram and electrocardiogram (bottom of the figure). The phonocardiogram shows one opening click (thick arrows), two closing clicks (thin arrows), and an ejection type systolic murmur. The vertical lines show the timing of the clicks in relation to the disc movements. The patient also had a Björk-Shiley mitral valve which produced three early diastolic clicks (asterisks) on opening. areas of the chest wall using both the diaphragm and the bell of the stethoscope and with the patient in the supine, left lateral, and sitting positions. We noted the quality, intensity, and variation of the prosthesis clicks as well as of the site at which they were loudest. We also noted the quality, intensity, localisation, and duration of any systolic or diastolic murmur.

\section{PHONOCARDIOGRAPHY AND \\ ECHOCARDIOGRAPHY}

The phonocardiographic recordings were made by means of a suction type IREX heart sound microphone and the fibreoptic strip chart recorder in an IREX System III echocardiograph. The microphone was placed over the site of the peak auscultatory intensity of the sound or murmur of interest not on any standard phonocardiographic area. The filter settings were chosen according to whether prosthesis clicks and high frequency murmurs or low frequency mitral murmurs were to be recorded. The chart speed was $100 \mathrm{~mm} / \mathrm{s}$.

The echocardiographic studies were performed with the IREX System III echocardiograph equipped with a medium focused $2.25 \mathrm{MHz}, 0.5$ inch transducer. The aortic valve studies were made either from the left parasternal area or from the right supraclavicular fossa, and the mitral studies from both the left parasternal and apical areas. Once the motion of the valve disc(s) was clearly seen on the $M$ mode screen it was recorded on dry silver paper simultaneously with an electrocardiogram and a phonocardiogram (see above) at a speed of 100 $\mathrm{mm} / \mathrm{s}$. Satisfactory echocardiograms were obtained from 17 of the 23 aortic valve prostheses and from 19 of the 22 mitral prostheses. The recordings were scrutinised visually to determine the timing of the valve clicks in relation to the movements of the disc.

\section{Results}

\section{LILLEHEI-KASTER VALVE}

The 11 Lillehei-Kaster valves were all in the aortic position. A single, low intensity opening click was heard in four patients and in another four the click could be recorded but not heard (Fig. 1). The closing sound invariably consisted of two parts, a sharp low intensity component and a high intensity metallic click (Fig. 1), that were readily distinguishable by attentive auscultation. A grade 2-3/6 ejection systolic murmur was heard in all patients. It usually filled most of systole, peaked at or slightly before mid-systole, and was quite harsh in some patients (Fig. 1). A palpable thrill was noted in one patient. A short early diastolic high frequency murmur of grade $1-2 / 6$ intensity was detected in four patients on auscultation but not on phonocardiography. 
BJ ORK-SHILEY VALVE

There were 15 Björk-Shiley valves in the mitral position. Both opening and closing sounds were invariably audible. The opening sound consisted of several sharp but faint clicks which produced a characteristic crackling sound in early diastole. Phonocardiography showed that there were two to three closely spaced opening clicks in each patient (Fig. 2a and $2 \mathrm{~b}$ ). The closing sound was usually heard as a
Fig. 2 Echophonocardiograms of Björk-Shiley mitral ( $a$, b) and aortic (c) valve prostheses. Two $(a, c)$ to three (b) opening clicks and one (b) or two $(a, c)$ closing clicks were recorded; the thick and thin arrows point at the opening and closing clicks respectively. single intense click (Fig. 2b), but a second minor click was distinguishable before the major closing sound in five patients (Fig. 2a). A grade 2/6 rumbling mid-diastolic murmur was heard and recorded in eight of 15 patients (Fig. 3).

One patient had a Björk-Shiley valve in the aortic position. Both the opening and closing sounds were heard in two parts, and a short grade $2 / 6$ early systolic murmur was detected as well (Fig. 2c). 


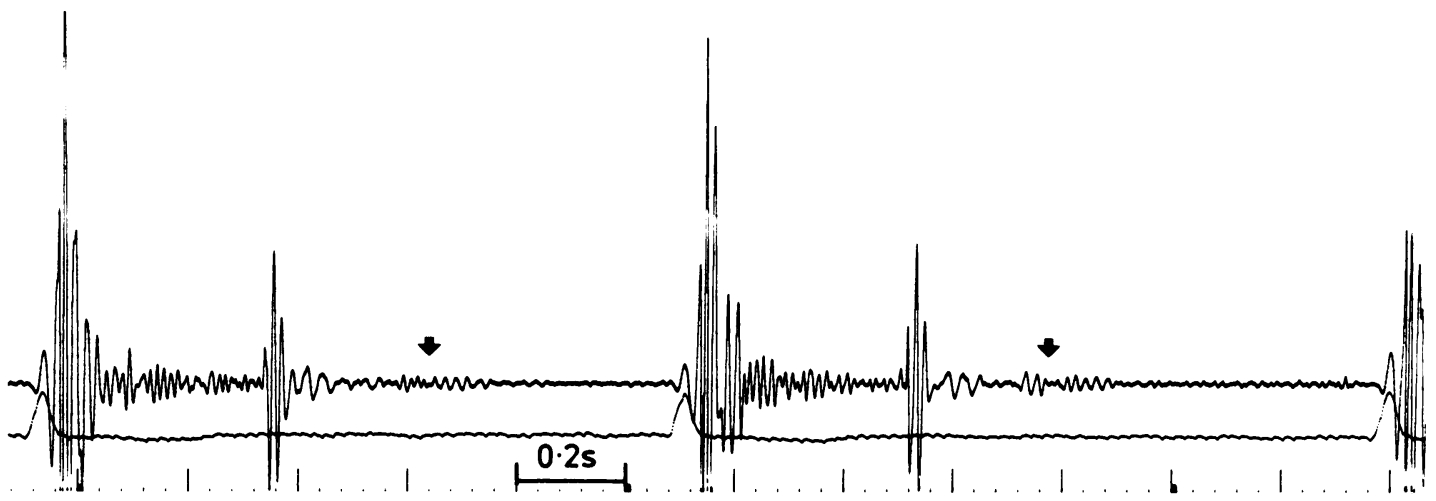

Fig. 3 A low frequency phonocardiogram showing the mid-diastolic rumble (arrow) in a patient with a Björk-Shiley mitral valve prosthesis. The rhythm is slow atrial fibrillation.

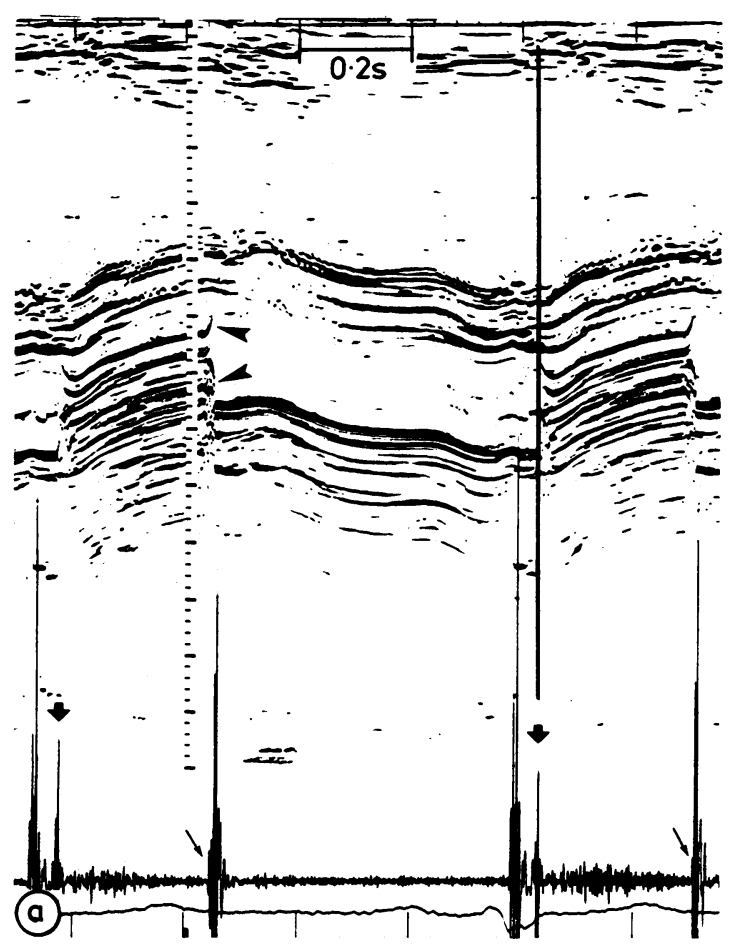

ST JUDE VALVE

There were 11 St Jude valves in the aortic position. An opening sound was always heard, usually as a single low intensity click (Fig. 4a), but two clicks were detectable in one patient (Fig. 5). The closing sound typically had two components (Fig. 5), but in two patients only one, high intensity click was found (Fig. 4a). A grade 2/6 short and soft early to mid-

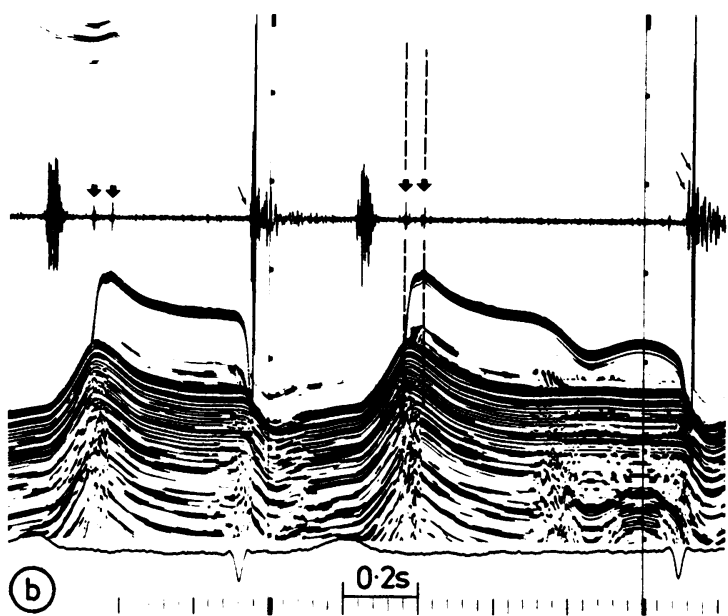

Fig. 4 Echophonocardiograms of St fude aortic ( $a$ ) and mitral (b) valve prostheses. The aortic valve produces one opening click and one closing click (a) whereas the mitral valve gives rise to two clicks on opening and one to two on closing (b). The opening and closing clicks are indicated by the thick and thin arrows respectively. The arrowheads show the two echoes from the leaflets of the aortic valve $(a)$. The mitral valve recording was made at an apical transducer position and therefore the motion of one leaflet only is seen (b).

systolic murmur was heard in all patients and a grade 1-2/6 early diastolic murmur in three.

Seven patients had a St Jude valve in the mitral position. A faint, crackling opening sound was heard on careful auscultation in all. Phonocardiography showed that the sound was composed of two or, rarely, three separate clicks of low intensity (Figs. 4b and 5). The closing sound was single in four patients 


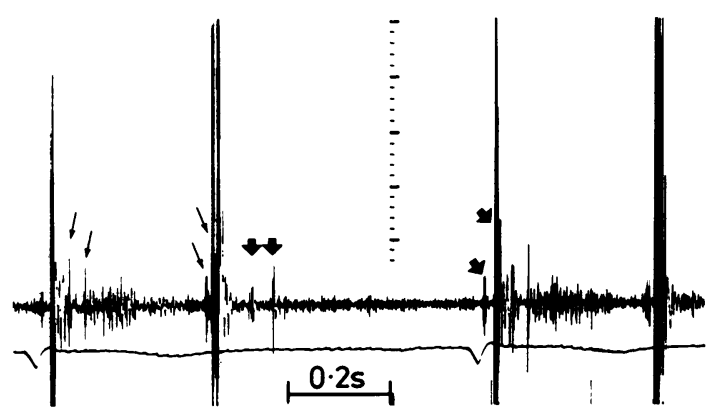

Fig. 5 A high frequency phonocardiogram of a patient with aortic and mitral St fude valves. Note the double opening and closing clicks from both the aortic (thin arrows) and mitral (thick arrows) valve prostheses.

and had two distinct components in three (Fig. 5). A grade $2 / 6$ mid-diastolic rumble was heard and recorded in four patients.

\section{GENERAL OBSERVATIONS}

The aortic valve clicks were heard best in the middle or lower left parasternal area. Also the mitral valve clicks were usually best distinguished in this area and only exceptionally over the cardiac apex. The intensity of both aortic and mitral valve opening sounds varied with respiration in some patients; their audibility was greatest at end expiration. The intensity of the mitral valve closing sound varied inversely with the duration of the preceding diastole in patients with atrial fibrillation. After prolonged $\underset{c}{\stackrel{c}{c}}$ pauses the normal closing sound of the Björk-Shiley valve, but not that of the bi-leaflet $S t$ Jude valve, was $\stackrel{\text { S? }}{+}$ on occasion absent and was replaced with a faint late $\bar{c}$ diastolic crackle that indicated presystolic valve closure (Fig. 6).

The diastolic murmurs produced by the mitral $\stackrel{ه}{\varnothing}$ Björk-Shiley and St Jude valves were similar in quality, intensity, and duration and resembled the $\vec{P}$ rumble of mild native valve mitral stenosis save for the lack of a presystolic component even in patients $\vec{\omega}$ in sinus rhythm. The murmur could be accurately $\Omega$ localised to the apical area and was most easily detected when the patient lay in the left lateral posi- of tion. The systolic murmurs from the aortic $\rightarrow$ prostheses were best heard in the left parasternal $\omega_{0}$ area. They were of an "innocent" nature in all pa- $\perp$ tients with a St Jude aortic prosthesis but resembled 윽 mild native valve aortic stenosis in several patients $\overrightarrow{-}$ with Lillehei-Kaster valves. Neither the presence $\frac{D}{0}$ nor the intensity of systolic or diastolic murmurs correlated with the prosthetic valve size.

The timing of the prosthetic valve clicks in re- $\stackrel{\infty}{\infty}$ lation to the disc movements on echocardiography was the same irrespective of the type or position of the prosthesis. Single opening or closing clicks coincided with the onset of the disc opening motion or with the completion of its closure. When multiple $\frac{\circ}{\Phi}$ clicks were detected, both the onset and the termi- $\stackrel{2}{\Rightarrow}$ nation of the disc opening or closing excursion had $\bar{\partial}$ their audible and recordable counterparts (Figs. 1, 2, 4 , and 6).

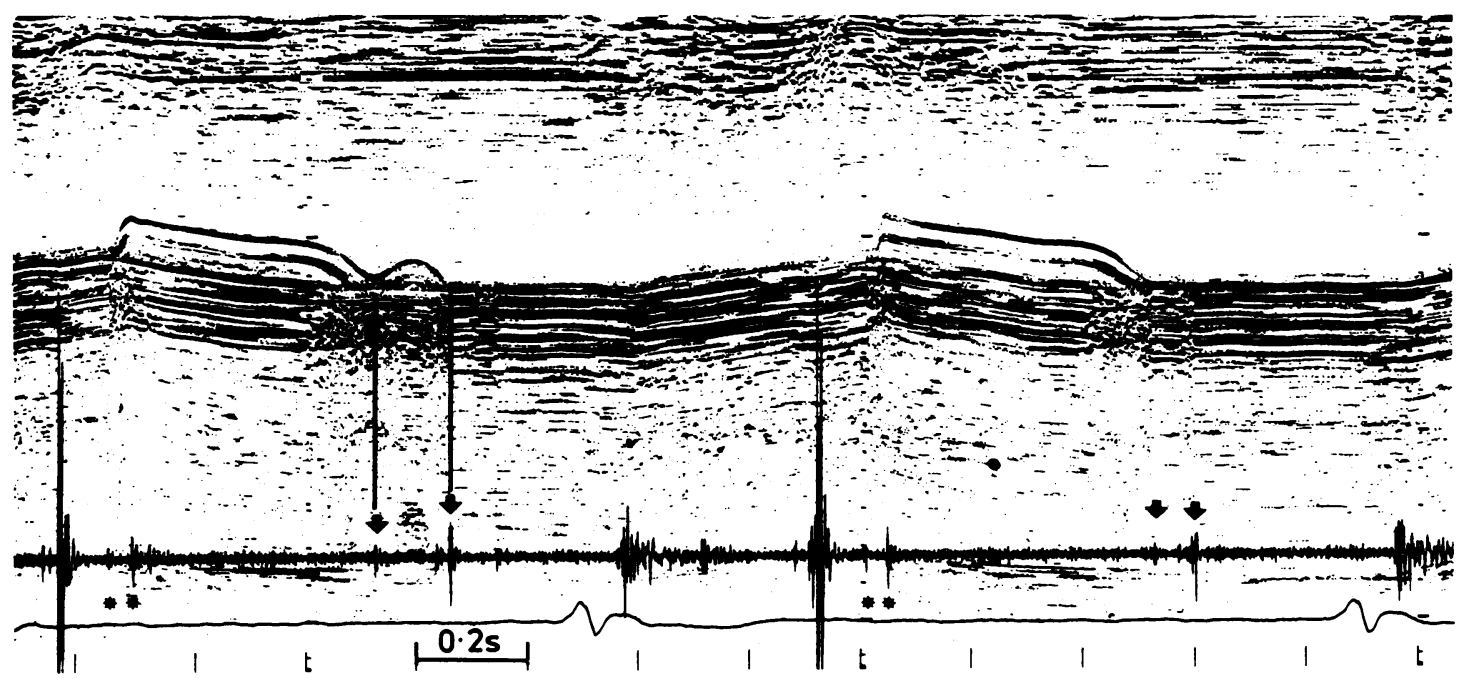

Fig. 6 Echophonocardiogram of a Björk-Shiley mitral valve in a patient who had slow atrial fibrillation. Note the presystolic valve closure and simultaneous small clicks (arrows) on the phonocardiogram. Two opening clicks are also recorded (asterisks). 


\section{Discussion}

\section{CLICKS}

It is well known that the tilting disc valve prostheses produce closing sounds which are distinct and easily detectable during routine cardiac auscultation. ${ }^{10}$ Their attenuation or loss in serial examinations indicate prosthesis malfunction, usually thrombosis or tissue ingrowth. ${ }^{1112}$ The present study adds to this knowledge by showing that irrespective of the type or position of the prosthesis the normal closing sound may be heard and recorded in two parts produced by the onset and termination of the disc closing excursion. In theory, loss of a previously detectable minor component of a closing sound could be the first signal of incipient valve thrombosis, but as yet we have no positive evidence to support this.

According to recent authoritative reviews, ${ }^{1013}$ the tilting disc valves produce little or no sound on opening. This belief is based on a few reports ${ }^{241415}$ which focused on echocardiographic examination and paid less attention to the details of phonocardiography, and often made no mention of auscultatory findings. ${ }^{41415}$ We have showed that apart from the Lillehei-Kaster valve, which can open silently, normally functioning tilting disc valves invariably produce audible and recordable sounds on opening. Furthermore, the opening sound may contain multiple clicks, particularly when the valve is in the mitral position. Smith et al, Feldman et al, and Raizada et al also found recordable opening clicks in patients with St Jude valve prostheses. ${ }^{101617}$ According to Smith et al the opening click of the St Jude aortic valve is recorded only after complete opening of the leaflets and is caused by turbulent transvalvar flow. ${ }^{10}$ We did not confirm their observation and cannot agree with their theory because we found that the opening clicks of the St Jude valve coincided either with onset alone or with onset and termination of the opening motion of the valve leaflets (Fig. 4). The clinical importance of tilting disc valve opening sounds has not been established, but some reports suggest that alterations in the opening sound may be an even more sensitive indication of evolving valve thrombosis than alterations in the closing sound. ${ }^{1819}$

\section{MURMURS}

Recordable murmurs are common in patients with normally functioning tilting disc valve prostheses. Gibson et al found mid-diastolic rumbles in 14 of 20 patients with Lillehei-Kaster mitral valves, ${ }^{2}$ and DePace et al recorded similar murmurs in six of 28 patients with St Jude mitral prostheses. ${ }^{4}$ In the present study, a rumbling mid-diastolic murmur was easily heard in more than $50 \%$ of patients with mitral valve prostheses and a systolic ejection type murmur was heard in all patients with aortic prostheses. These "normal" murmurs indicate turbulent flow and may partly result from the small pressure gradients present across all types of artificial valves. ${ }^{20}$ Any prolonged diastolic mitral rumble or a delayed peak systolic aortic valve murmur are abnormal and suggest prosthesis obstruction. ${ }^{19}$ The systolic murmur produced by the Lillehei-Kaster prosthesis in the aortic position was clearly more intense and longer in duration than that produced by the St Jude at the same site. This can be accounted for by the higher pressure gradients measured across the Lillehei-Kaster valve in the aortic position. ${ }^{20}$

Evidence from the present study supports the view that short early diastolic murmurs may sometimes be heard in patients with apparently normally functioning tilting disc aortic valve prostheses. ${ }^{10}$ These murmurs result from the mild regurgitation permitted by the valve design. ${ }^{20}$ Any murmur extending into the latter half of diastole or associated with other signs of aortic insufficiency should arouse suspicion of paravalvar regurgitation. Although tilting disc mitral valve prostheses may generate soft systolic murmurs, ${ }^{2}$ their normal auscultatory characteristics do not include a pansystolic mitral regurgitant murmur of any intensity.

\section{Conclusions}

Normally functioning Lillehei-Kaster, BjörkShiley, and St Jude heart valve prostheses generate characteristic and easily recognisable auscultatory findings. Distinct and frequently double clicks are heard on valve closing and, apart from the LilleheiKaster valve which not uncommonly opens silently, these valves also regularly produce audible sounds on opening. Multiple opening clicks do not indicate prosthesis malfunction. In the aortic position these valves always give rise to early or mid-systolic murmurs, and on occasion a short early diastolic murmur may be heard as well. Mitral valve prostheses produce mid-diastolic rumbles in more than half the patients. Familiarity with these normal findings should help clinicians to take full advantage of the auscultatory findings when examining patients with these prostheses.

\section{References}

1 Najmi M, Segal BL. Auscultatory and phonocardiographic findings in patients with prosthetic ballvalves. Am f Cardiol 1965; 16: 794-9.

2 Gibson TC, Starek PHK, Moos S, Craige E. Echo- 
cardiographic and phonocardiographic characteristics of the Lillehei-Kaster mitral valve prosthesis. Circulation 1974; 49: 434-40.

3 Cunha CLP, Giuliani ER, Callahan JA, Pluth JR. Echophonocardiographic findings in patients with prosthetic heart valve malfunction. Mayo Clin Proc 1980; 55: 231-42.

4 DePace NL, Kotler MN, Mintz GS, Lichtenberg L, Goel IP, Segal BL. Echocardiographic and phonocardiographic assessment of the St. Jude cardiac valve prosthesis. Chest 1981; 80: 272-7.

5 Weinstein IR, Marbarger JP, Pérez JE. Ultrasonic assessment of the St Jude prosthetic valve: $M$ mode, two-dimensional, and Doppler echocardiography. Circulation 1983; 68: 897-905.

6 Nitter-Hauge S. Doppler echocardiography in the study of patients with mitral disc valve prostheses. $\mathrm{Br}$ Heart $\mathcal{f} 1984$; 51: 61-9.

7 Sands MJ, Lachman AS, O'Reilly DJ, Leach CN, Sappington JB, Katz AM. Diagnostic value of cinefluoroscopy in the evaluation of prosthetic heart valve dysfunction. Am Heart $\mathcal{F} 1982$; 104: 622-7.

8 Verdel G, Heethaar RM, Jambroes G, van der Werf T. Assessment of the opening angle of implanted BjörkShiley prosthetic valves. Circulation 1983; 68: 355-9.

9 Mintz GS, Carlson EB, Kotler MN. Comparison of noninvasive techniques in evaluation of the nontissue cardiac valve prosthesis. Am f Cardiol 1982; 49: 39-44.

10 Smith ND, Raizada V, Abrams J. Auscultation of the normally functioning prosthetic valve. Ann Intern Med 1981; 95: 594-8.
11 Ben-Zvi J, Hildner FJ, Chandraratna PA, Samet P. Thrombosis on Björk-Shiley aortic valve prosthesis. Am $\mathcal{f}$ Cardiol 1974; 34: 538-44.

12 Commerford PJ, Lloyd EA, De Nobrega JA. Thrombosis of St Jude Medical cardiac valve in the mitral position. Chest 1981; 80: 326-7.

13 Craige E. Heart sounds. In: Braunwald E, ed. Heart disease. Philadelphia: WB Saunders, 1984: 40-67.

14 Vardan S, Warner R, Mookheriee S, Mead M, Obeid AI. Echo- and phono-cardiographic studies in patients with Lillehei-Kaster aortic valve prostheses. Ipn Heart f 1979; 20: 277-88.

15 Amann FW, Burckhardt D, Hasse J, Grädel E. Echocardiographic features of the correctly functioning $\mathrm{St}$ Jude medical valve prosthesis. Am Heart $\mathcal{F} 1981$; 101: 45-51.

16 Feldman HJ, Gray RJ, Chaux A, et al. Noninvasive in vivo and in vitro study of the St. Jude mitral valve prosthesis. Am f Cardiol 1982; 49: 1101-9.

17 Raizada V, Smith ND, Hoyt TW, et al. Phonocardiographic characteristics of the St. Jude prosthesis in the aortic position. Chest 1982; 81: 95-6.

18 Copans H, Lakier JB, Kinsley RH, Colsen PR, Fritz VU, Barlow JB. Thrombosed Björk-Shiley mitral prostheses. Circulation 1980; 61: 169-74.

19 Witchitz S, Veyrat C, Moisson P, Scheinman N, Rozenstajn L. Fibrinolytic treatment of thrombus on prosthetic heart valves. Br Heart $\mathcal{f} 1980$; 44: 545-54.

20 McClung JA, Stein JH, Ambrose JA, Herman MV, Reed GE. Prosthetic heart valves: a review. Prog Cardiovasc Dis 1983; 26: 237-70. 